\title{
INFECÇÃO LATENTE DE SÍTIO CIRÚRGICO: HIPÓTESE OU REALIDADE?
}

\section{LATENTE SURGICAL SITE INFECTION : HYPOTHESIS OR REALITY?}

\author{
Álvaro Antônio Bandeira Ferraz, TCBC-PE ${ }^{1}$ \\ Edmundo Machado Ferraz, TCBC-PE ${ }^{2}$
}

\begin{abstract}
RESUMO: Objetivo: A infecção prévia do sítio cirúrgico é um forte determinante para o desenvolvimento de uma nova infecção do sítio cirúrgico. É a chamada infecção latente do sítio cirúrgico. O objetivo deste estudo foi de analisar a taxa de infecção de pacientes com história prévia de infecção do sítio cirúrgico e tentar correlacionar com o agente etiológico da infecção anterior. Método: A população estudada compreendeu 389 pacientes submetidos ao tratamento cirúrgico eletivo de hérnia incisional. Os dados foram analisados de acordo com as informações contidas na ficha de controle de infecção, que é anexada ao prontuário de cada paciente, sendo, após a alta encaminhada à Comissão de Controle de Infecção Hospitalar. Resultados: A incidência de infecção do sítio cirúrgico foi de 6,7\% (26/389). Nos pacientes com história pregressa de infecção de ferida operatória (69/389) um novo quadro de infecção ocorreu em 27,6\%(19/69) enquanto que a taxa de infecção de feridas dos pacientes que não apresentaram episódios anteriores de infecção de sítio cirúrgico foi de 2,2\% (7/320). Esta diferença foi estatisticamente significativa ( $p<0,001)$. Nos 19 pacientes que apresentaram infecção do sítio cirúrgico e história pregressa de infecção do sítio cirúrgico, conseguimos resgatar apenas cinco culturas (quatro Staphyloccocus aureus e um Proteus sp). Houve coincidência de culturas em quatro ocasiões (quatro Staphyloccocus aureus). Conclusões: No estudo apresentado, observamos uma diferença estatisticamente significativa entre a taxa de infecção nos paciente com historia de infecção de ferida operatória prévia $(27,6 \%$ contra $2,2 \%)$. Este dado nos leva a considerar a possibilidade da existência da infecção latente de sítio cirúrgico.
\end{abstract}

Descritores: Infecção; Infecção da ferida operatória; Hérnia ventral.

\section{INTRODUÇÃO}

Apesar de inúmeros fatores de risco estarem associados a hérnia incisional, tais como, obesidade, idade avançada, desnutrição, ascite, diálise perito- neal, outras condições que aumentam a tensão na parede abdominal, uso de corticóides e quimioterápicos, a infecção do sítio cirúrgico tem sido relacionada como o principal fator causal das hérnias incisionais ${ }^{1-6}$.

1. Professor Adjunto do Departamento de Cirurgia da Universidade Federal de Pernambuco (UFPE); Chefe da Unidade de Transplantes do HC da UFPE; Mestre e Doutor em Medicina pela UFPE; Especialização em Infecção em Cirurgia no Medical College of Wisconsin - EUA; Pós-Doutorado em Transplante de Fígado na Universidade de Miami - EUA.

2. Professor Titular de Cirurgia Abdominal e Bases da Técnica Cirúrgica da UFPE; Chefe do Serviço de Cirurgia Geral do Hospital das Clínicas da UFPE; Doutor e Livre Docente pela UFPE; Fellow do American College of Surgeons (FACS) e da Surgical Infection Society. 
A hernioplastia incisional é um procedimento classificado como limpo pelo CDC, American College of Surgeons e pelo Colégio Brasileiro de Cirurgiões, no entanto, a incidência de complicações infecciosas do sítio cirúrgico é estatisticamente maior do que outras cirurgias limpas. Alguns fatores têm sido responsabilizados por este maior índice, tais como, descolamento excessivo, alta incidência de seromas e hematomas, presença de espaço morto e mais recentemente, pela presença de episódios anteriores de infecção de ferida ${ }^{7,8}$.

Ferraz et al. ${ }^{7}$ chamaram a atenção deste fato e determinaram que nas hernioplastias incisionais a introdução da antibioticoprofilaxia, em dose única, é capaz de reduzir de maneira estatisticamente significativa a taxa de infecção de ferida operatória. Bactérias viáveis podem estar presentes em uma ferida cicatrizada por vários anos ${ }^{9-11}$ e deste modo, representar um fator considerável ao desenvolvimento de um novo episódio de infecção.

A hipótese apresentada é a de que a infecção prévia do sítio cirúrgico é um forte determinante para o desenvolvimento de uma nova infecção do sítio cirúrgico, quando da mesma via cirúrgica de acesso. É a chamada infecção latente do sítio cirúrgico ${ }^{1,12}$.

O objetivo deste estudo é analisar a taxa de infecção de pacientes com história prévia de infecção do sítio cirúrgico e tentar correlacionar com o agente etiológico da infecção anterior.

\section{MÉTODO}

A população estudada compreendeu 389 pacientes submetidos, no Serviço de Cirurgia Geral do Hospital das Clínicas da UFPE, ao tratamento cirúrgico eletivo da hérnia incisional, no período compreendido entre Janeiro de 1986 a Dezembro de 1999. Foram considerados apenas os pacientes submetidos apenas à correção do defeito herniário. Pacientes submetidos a procedimentos simultâneos foram excluídos desta casuística.

A cirurgia inicial, realizada anteriormente ao surgimento da hérnia incisional, foi de origem ginecológica ou obstétrica em 173 pacientes, laparotomias exploradoras em 42 , cirurgia para tratamento de hérnia abdominal em 33, apendicectomias em 16, colecistectomias em 32 e em 93 pacientes, outros procedimentos.

O tempo de evolução da hérnia incisional (data do diagnóstico - data da cirurgia), foi em média de 42,2 meses (Valor mínimo = cinco meses; valor máximo $=444$ meses $)$.

A duração média do procedimento cirúrgico foi de 111,1 $\pm 46,2$ minutos. O uso de tela ocorreu em 55 pacientes, e drenagem fechada a vácuo foi utilizada em 202 pacientes.

Os dados foram analisados de acordo com as informações contidas na ficha de controle de infecção, que é anexada ao prontuário de cada paciente, sendo, após a alta encaminhada à Comissão de Controle de Infecção Hospitalar do HC da UFPE. Os dados constantes na ficha de controle de infecção foram obtidos através de um sistema de busca ativa realizado pelo corpo de enfermagem da Comissão de Controle de Infecção, que examina os pacientes e sua ferida operatória quando da estada do paciente no hospital. Por ocasião da alta hospitalar os pacientes foram encaminhados ao ambulatório de egressos da CCIH, que centraliza o retorno de todos os pacientes cirúrgicos do hospital. Neste ambulatório examinase o estado da ferida, realiza-se curativos, retira-se os pontos e acompanha o paciente cirúrgico após a alta hospitalar. O retorno a este ambulatório se dá em torno do décimo ao $15^{\circ}$ dia de pós-operatório. Os pacientes são seguidos pela Comissão de Controle de Infecção até o $30^{\circ}$ dia de pós-operatório ${ }^{13,14}$.

Quando da admissão, os pacientes eram examinados e orientados no que se refere ao banho com lavagem da cabeça e do local da cirurgia e da tricotomia 1-2 horas antes do procedimento. A identificação de infecção comunitária determinava a suspensão do procedimento eletivo.

A presença de pus foi o critério utilizado para classificar a ferida como infectada.

A utilização de antimicrobianos segue a política de controle do Hospital das Clínicas da UFPE 13,15. Nas hernioplastias incisionais indica-se a utilização profilática em dose única, na indução anestésica, com uma cefalosporina de primeira geração, do tipo Cefazolina. Quando as cirurgias se estenderam por um tempo acima de 120 minutos uma segunda dose foi administrada. Não foi mantido antimicrobiano após o término do procedimento cirúrgico.

O grupo estudado constava de 73 pacientes do sexo masculino e 316 do sexo feminino; com idade variando de 23 até 88 anos (idade média de 49,9 anos).

Os dados foram analisados estatisticamente, através do teste de Qui-quadrado, com nível de significância de $<0,05$ e intervalo de confiança de $95 \%$. A 
análise foi feita com auxilio de softwares $\left(\right.$ Excel ${ }^{\circledR}$ e Statistica ${ }^{\circledR}$.

\section{RESULTADOS}

No período de Janeiro de 1986 a Dezembro de 1999 a taxa de infecção do sítio cirúrgico em cirurgia limpa foi de $4,6 \%$, enquanto que nas hernioplastias incisionais esta taxa foi de $6,7 \%$. Esta diferença não foi estatisticamente significativa $(p=0,069)$.

Dentre os 389 pacientes submetidos a hernioplastia incisional, $69(17,7 \%)$ apresentaram episódio anterior de infecção do sítio cirúrgico.

A incidência de infecção do sítio cirúrgico foi de 6,7\% (26/389). Nos pacientes com história pregressa de infecção de ferida operatória (69/389) um novo quadro de infecção ocorreu em 27,6\%(19/ 69) enquanto que a taxa de infecção de feridas dos pacientes que não apresentaram episódios anteriores de infecção de sítio cirúrgico foi de 2,2\%(7/320). Esta diferença foi estatisticamente significativa $(\mathrm{p}<$ $0,001)$.

Staphyloccocus aureus foi a bactéria mais freqüente nas infecções do sítio operatório, correspendendo à $42,9 \%$ das culturas, seguida de Klebisiella sp e Staphyloccocus epidermidis com $21,5 \%$ e 14,3\% respectivamente. E.coli, Proteus sp e Enteroccocus $s p$, com $7,1 \%$ cada completaram as culturas positivas.

Nos 19 pacientes que apresentaram infecção do sítio cirúrgico e história pregressa de infecção do sítio cirúrgico, conseguimos resgatar apenas cinco culturas (quatro Staphyloccocus aureus e um Proteus $s p$ ). Houve coincidência de culturas em quatro ocasiões (quatro Staphyloccocus aureus).

\section{DISCUSSÃO}

Quando analisamos o nosso material de 389 hernioplastias incisionais, identificamos como fatores de risco ao desenvolvimento de complicações infecciosas, a duração da cirurgia acima de duas horas, permanência do dreno a vácuo por mais de dois dias, e a utilização de tela. Além destes um outro dado nos chamou atenção, a história pregressa de infecção de ferida foi um importante fator de risco ao desenvolvimento de um novo episódio infeccioso ${ }^{16}$.

O perfil bacteriológico das infecções do sítio cirúrgico foi similar aos demais casos de nossa Instituição ${ }^{14}$.
Em 1989, Houck et al. ${ }^{1}$ chamaram a atenção para um fator de risco antes ignorado. A história prévia de infecção do sítio cirúrgico fez elevar o risco de uma nova infecção de maneira significativa. É relatado uma taxa de $41 \%$ de infecção do sítio cirúrgico em pacientes com história pregressa de infecção e, de $12 \%$ em pacientes sem história pregressa de infecção, mesmo após a completa cicatrização da pele e a total ausência de sinais de infecção cutânea.

Hesselink et al. ${ }^{17}$ também chamam a atenção para este fato apesar de não terem apresentado uma diferença estatisticamente significativa.

No nosso estudo observamos uma diferença estatisticamente significativa entre a taxa de infecção nos paciente com historia de infecção de ferida operatória prévia $(27,6 \%$ contra $2,2 \%)$. Este dado nos leva a considerar a possibilidade, da existência da infecção latente de sítio cirúrgico.

Em 1976, Sampsel ${ }^{10}$ chamou a atenção pela primeira vez, para casos de infecção de ferida operatória desenvolvida por mais de 15 anos depois da agressão cirúrgica e em ferida totalmente cicatrizadas. Na época foi atribuída à contaminação persistente dos fios de sutura não absorvíveis.

Davis et al, em $1982^{11}$ relataram 26 pacientes que desenvolveram infecção do sítio cirúrgico com mais de seis meses após o ato cirúrgico. Os autores concluíram que as bactérias foram introduzidas na ferida no momento da cirurgia, permaneceram latentes durante anos, e, com a quebra dos mecanismos de defesa ou imunológicos do paciente desenvolveram infecção.

Como a maioria dos pacientes portadores de hérnia incisional são encaminhados de outras instituições, muitas delas do interior do Estado e de outras cidades do Nordeste, conseguimos resgatar apenas cinco resultados de culturas do episódio prévio de infecção de ferida. A coincidência de $80 \%$ (4/5) das culturas, em nosso material, não significa que as bactérias sejam necessariamente as mesmas. Apenas o resultado do DNA bacteriano poderia confirmar esta hipótese. Houck et al ${ }^{1}$ relataram uma coincidência bacteriana de 71,4\% (5/7). Apesar do número pequeno de culturas, este alto percentual de coincidência de agente etiológico não deve ser desprezado.

A hipótese levantada de que a infecção de uma ferida poderá determinar a colonização durante anos, por bactérias viáveis, e de que novas agressões ou a queda nos mecanismos de defesa do paciente, 
poderia favorecer o desenvolvimento de novas infecções do sítio cirúrgico ou até de sítios a distância, faz com que algumas indagações surjam no manuseio deste tipo de paciente:

1)- Devemos classificar uma cirurgia com antecedentes de infecção do sítio cirúrgico como limpa? Devemos reclassificar feridas previamente infectadas como potencialmente contaminadas ou até mesmo contaminadas?

2)- Deve-se ou não tratar, de maneira tópica ou sistêmica, todos os casos com história de infecção pregressa do sítio cirúrgico com o intuito de eliminar a contaminação latente da ferida operatória ?

3)- Que cuidados deveremos tomar nos casos de infecção prévia da ferida operatória?

É importante salientar com relação a este ponto, que foi utilizado de rotina o antibiótico profilático em todos os pacientes submetidos a hernioplastia incisional. Neste estudo a utilização da antibioticoterapia profilática não foi capaz de diminuir a incidência de nova complicação infecciosa no sítio cirúrgico. Deste modo, torna-se claro que o conhecimento do perfil de antibiograma dos germes cultivados no primeiro episódio infecciosos poderá, trazer subsídios importantes na escolha de um antimicrobiano profilático a ser utilizado, na nova cirurgia.

Uma opção que poderia ser considerada é o tratamento com antibiótico de longa duração da infecção do sítio cirúrgico, mesmo que esta infecção não determine alterações sistêmicas e que sejam infecções restritas à ferida. $\mathrm{O}$ tratamento prolongado com antibióticos poderia inviabilizar estas bactérias de se tornarem latentes.

Estas perguntas ainda não têm respostas. No entanto, com os avanços no campo da biologia molecular e estudos de DNA das bactérias podemos vislumbrar que num futuro próximo poderemos comprovar ou não a teoria da infecção latente, e responder algumas destas indagações.

\begin{abstract}
Background: Previous infections of the surgical site play an important role on the development of a new infection of the surgical site. This is named latent infection of the surgical site. The aim of this study was to analyze the infection rate of patients with previous history of surgical site infection and to relate it to the etiologic agent of the anterior infection. Methods: The authors studied 389 patients submitted to an elective incisional hernia repair. The data were acquired through an active search system and stored in a formulary page inside the patients records. After discharge the Infection Control Committee analysed those data. Results: The surgical site infection rate was 6.7\% (26/389). In the patients with previous history of surgical site infection (69/389) a new wound infection occurred in 27,6\%(19/69) compared with 2,2\% (7/320) of the patients without anterior infection episodes. This difference was statistically significant $(p<0.001)$. In the 19 patients with previous wound infection and a reinfection episode the authors recovered five cultures (four Staphyloccocus aureus $e$ one Proteus sp). In four cases identical organisms were cultured from the original wound infection (four Staphyloccocus aureus). Conclusion: The authors concluded that a previous episode of surgical site infection increases the risk of a new wound infection episode $(27,6 \% \times 2,2 \%, p<0,001)$. This data suggest the existence of a latent wound infection.
\end{abstract}

Key words: Infection; Surgical wound infection; Ventral hernia.

\title{
REFERÊNCIAS
}

1. Houck JP, Rypins EB, Sarfeh IJ, et al. - Repair of incisional hernia. Surg Gynecol Obstet, 1989, 169(5): 397-399.

2. Bucknall TE, Cox PJ, Ellis H. - Burst abdomen and incisional hernia: a prospective study of 1129 major laparotomies. BMJ, 1982, 284(6320): 931-933.
3. Mudge M, Hughes LE. - Incisional hernia: a 10 year prospective study of incidence and attitudes. Br J Surg, 1985, 72(1): 70-71.

4. Sabiston DC. Tratado de Cirurgia - As bases biológicas da prática cirúrgica moderna. $15^{\mathrm{a}}$ Edição. Rio de Janeiro. Guanabara Koogan, 1999, pp. 1130-1146 
5. White TJ, Santos MC, Thompson JS. - Factors affecting wound complications in repair of Ventral Hernias. Am Surg, 1998, 64(3): 276-280.

6. Luijendijk RW, Hop WC, van den Tol MP, et al. - A comparison of suture repair with mesh repair for incisional hernia. N Engl J Med, 2000, 343(6): 392398.

7. Ferraz EM, Bacelar TS, Aguiar JL, et al. - Wound infection rates in clean surgery: a potentially misleading risk classification. Infect Control Hosp Epidemiol, 1992, 13(8): 457-462.

8. Ferraz EM. Infecção da ferida na cirurgia do aparelho digestivo. Dissertação (Prof. Titular) - Recife. Universidade Federal de Pernambuco. 1990.

9. Haff RC, Griffin RP - Delayed wound infection. Case reports. Mo Med, 1967, 64(10): 854-855.

10. Sampsel JW. - Delayed and recurring infection in postoperative abdominal wounds. Am J Surg, 1976, 132(3): 316-319.

11. Davis JM, Wolff B, Cunninghan TF. - Delayed wound infection. An 11- year survey. Arch Surg, 1982, 117(2): 113-117.

12. Shilov AB. - Causes and prevention of latent infection in abdominal surgery. Vestn Khir Im II Grek, 1981, 127(7): 15-27.
13. Ferraz EM, Ferraz AA, Coelho HS, et al. - Postdischarge surveillance for nosocomial wound infection: does judicious monitoring find cases? Am J Infect Control, 1995, 23(5): 290-294.

14. Ferraz EM, Ferraz AA, Bacelar TS, et al. - Controle de infecção em cirurgia geral - Resultado de um estudo prospectivo de 23 anos e 42.274 cirurgias. Rev Col Bras Cir, 2001, 28(1): 17-26.

15. Ferraz EM, Ferraz AA - Antibioticoprofilaxia. In Ferraz EM. Infecção em cirurgia. Rio de Janeiro MEDSI, 1997, pp. 345-352.

16. Nadler LA, Sette M, Mathias CA, et al. - Fatores de risco para complicações infecciosas nas hernioplastias incisionais. Rev Col Bras Cir, 2001, 28:354.

17. Hesselink VJ, Luijendijk RW, de Wilt JH, et al. - An evaluation of risk factors in incisional hernia recurrence. Surg Gynecol Obstet, 1993, 176(3):228-234.

Endereço para correspondência:

Dr. Álvaro Antônio Bandeira Ferraz

Av. Beira Rio 240, Apto 2501

50750-400 - Madalena - Recife-PE

Tel. 081- 3227.29.91 Fax.: 081- 3271.15.26

E-mail: aabf@truenet.com.br 